\title{
Hereditary Persistence of Fetal Hemoglobin
}

National Cancer Institute

\section{Source}

National Cancer Institute. Hereditary Persistence of Fetal Hemoglobin. NCI Thesaurus. Code C129072.

The persistence of substantial fetal hemoglobin production into adulthood, usually associated with hemog lobinopathies due to mutations in the alpha and/or beta chain of hemoglobin. 